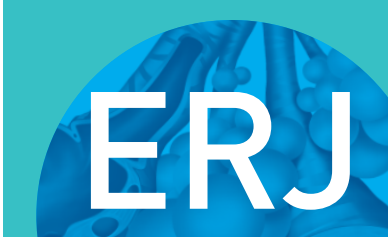

open research
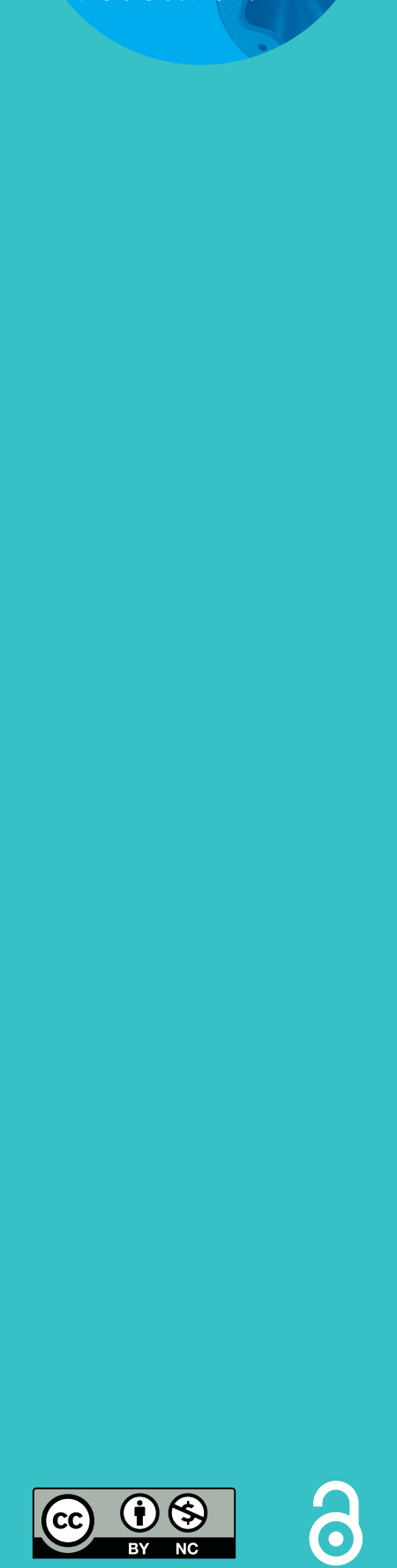

\section{Direct oral anticoagulant therapy in patients with morbid obesity after intermediate- or high-risk pulmonary emboli}

\author{
Daniel J. Lachant (1) ${ }^{1}$, Christina Bach ${ }^{1}$, Alexander Fe ${ }^{1}$, R. James White $\mathbb{1}^{1}$ and \\ Neil A. Lachant ${ }^{2}$
}

Affiliations: ${ }^{1}$ Division of Pulmonary and Critical Care Medicine, University of Rochester Medical Center, Rochester, NY, USA. ${ }^{2}$ Division of Hematology at The Wilmot Cancer Center, University of Rochester Medical Center, Rochester, NY, USA.

Correspondence: Daniel J. Lachant, Mary Parkes Allergy and Asthma Center, 400 Red Creek Dr Suite 110, Rochester, NY 14623, USA. E-mail: Daniel_LachantQurmc.rochester.edu

ABSTRACT There is little reported on the efficacy and safety of direct oral anticoagulants (DOACs) in morbid obesity after venous thromboembolism (VTE).

In this observational study, patients were followed up after intermediate- or high-risk pulmonary embolism (PE) at the University of Rochester Pulmonary Hypertension Clinic 2-4 months after the initial event. All patients had echocardiography and V/Q imaging regardless of symptoms. Outcomes of interest were the rates of recurrent VTE, thrombus resolution and development of chronic thromboembolic pulmonary hypertension (CTEPH) in patients with morbid obesity treated with a DOAC compared to treatment with vitamin $\mathrm{K}$ antagonists and to non-morbidly obese patients after PE. Using the electronic medical record, recurrent events were assessed up to 12 months after the event.

107 patients (body mass index $(\mathrm{BMI})>40 \mathrm{~kg} \cdot \mathrm{m}^{-2}, \mathrm{n}=32 ; \mathrm{BMI} 30-39.9 \mathrm{~kg} \cdot \mathrm{m}^{-2}, \mathrm{n}=39 ; \mathrm{BMI}<30 \mathrm{~kg} \cdot \mathrm{m}^{-2}$, $\mathrm{n}=36$ ) attended follow-up appointments after treatment for PE. A DOAC was used in 70 patients $\left(\mathrm{BMI}>40 \mathrm{~kg} \cdot \mathrm{m}^{-2}, \mathrm{n}=19 ;\right.$ BMI $\left.30-39.9 \mathrm{~kg} \cdot \mathrm{m}^{-2}, \mathrm{n}=27 ; \mathrm{BMI}<30 \mathrm{~kg} \cdot \mathrm{m}^{-2}, \mathrm{n}=24\right)$. There were no recurrent events within the first 12 months of initial diagnosis based on symptoms and imaging in any patient. There was no difference in rate of residual unmatched perfusion defect with DOACs or conventional anticoagulation (49\% versus $49 \%$ ). This finding remained in the subset of morbidly obese patients $(47 \%$ versus $50 \%$ ). For the overall cohort, there was no difference in the rate of CTEPH development based on anticoagulation with a DOAC ( $5 \%$ versus $8 \%$ with warfarin). There were no major bleeding complications with a DOAC.

DOAC therapy appears to be effective and safe in morbid obesity even after intermediate- or high-risk PE.

@ERSpublications

Direct oral anticoagulants appear to be safe and effective in the management of acute pulmonary embolism in morbidly obese patients https://bit.ly/2J1unqn

Cite this article as: Lachant DJ, Bach C, Fe A, et al. Direct oral anticoagulant therapy in patients with morbid obesity after intermediate- or high-risk pulmonary emboli. ERJ Open Res 2021; 7: 00554-2020 [https://doi.org/10.1183/23120541.00554-2020].

Received: 4 Aug 2020 | Accepted after revision: 17 Nov 2020

Copyright $\odot$ ERS 2021. This article is open access and distributed under the terms of the Creative Commons Attribution Non-Commercial Licence 4.0. 


\section{Introduction}

Direct oral anticoagulants (DOACs) used for the treatment of venous thromboembolism (VTE) have been available for almost a decade and are recommended over vitamin $\mathrm{K}$ antagonist therapy in the treatment of VTE $[1,2]$. There are two classes of DOACs currently approved for treatment of VTE: direct thrombin inhibitors (dabigatran [3]) and direct Xa inhibitors (rivaroxaban [4], apixaban [5] and edoxapan [6]). However, despite the clear advantages, DOACs are not often used in morbidly obese patients. The International Society of Thrombosis and Haemostasis (ISTH) recommends against DOAC use in patients with a body mass index $(\mathrm{BMI}) \geqslant 40 \mathrm{~kg} \cdot \mathrm{m}^{-2}$ or weight $>120 \mathrm{~kg}$ because of the lack of available safety and efficacy data. Further, if they are used, the ISTH recommends checking anti-Xa levels [7], even though therapeutic ranges have not been established for any DOAC. Interestingly, BMI and weight were not exclusionary criteria in any of the DOAC trials, and there is no evidence that DOAC therapy is ineffective in morbidly obese patients. Unfortunately, this ISTH consensus has led many providers to avoid DOAC therapy in morbid obesity, and these patients are frequently treated with warfarin despite the significant challenges in achieving therapeutic levels [8].

With the growing obesity epidemic, almost $40 \%$ of US adults are considered obese [9] and 7\% are considered morbidly obese with a $\mathrm{BMI} \geqslant 40 \mathrm{~kg} \cdot \mathrm{m}^{-2}[10]$. Obesity is not only an independent risk factor for VTE [11-13] but is also associated with an increased risk for recurrent VTE [14]. Morbid obesity is even more prevalent among hospitalised patients (one estimate of $16 \%$ [15]), many of whom are likely to require some anticoagulation therapy during hospitalisation. Therefore, an effective and easy to manage anticoagulation strategy in this population is critical to decrease their risk for long-term complications, including recurrent VTE. Our institutional approach to intermediate- and high-risk pulmonary embolism (PE) [16] includes programmatic follow-up for the majority of patients, many of whom are morbidly obese. We thus had an opportunity to address disease recurrence among people treated with DOACS and we performed a single-centre study observing the efficacy and safety of DOAC and warfarin therapy. In particular, we explicitly compared morbidly obese with obese and non-obese patients.

\section{Methods}

This was an initially retrospective and subsequently prospective observational cohort study evaluating imaging and clinical outcomes after inpatient management for an intermediate- or high-risk PE at the University of Rochester Medical Center, NY, USA, between November 2016 and June 2019. The study protocol (00003058) was approved by the University of Rochester Medical Center Institutional Review Board. Beginning in August 2017, at the time of hospital discharge for an acute intermediate- or high-risk PE [16], all patients with estimated survival $>1$ year (based on the assessment of the discharging physician) were offered follow-up at our Pulmonary Hypertension Association-accredited Comprehensive Care Center. We scheduled a V/Q scan, echocardiogram and office visit to assess for PE resolution or recurrent thrombosis. PE on initial computed tomography angiography was classified as saddle, main, lobar or segmental depending on the location of the most proximal clot. Ventilation perfusion scans were performed using $30 \mathrm{mCi}$ of aerosolised technetium (Tc)-99m-diethylene-triamine-pentaacetate followed by intravenous administration of 2-4 mCi Tc-99m-macroaggregated albumin. Six standard projections were obtained for both sets of images using a large field of view dual-head $\gamma$-camera fitted with general purpose parallel hole collimators, for a minimum of 100000 counts per ventilation image and 500000 counts per perfusion image. Residual unmatched perfusion defects at follow-up were defined as mismatched or partly mismatched segmental ventilation-perfusion defects. Board-certified cardiologists using standardised criteria [17] interpreted the echocardiograms. The pulmonary hypertension physicians (D.J.L. and R.J.W.) made clinical and functional assessments. Once patients were optimised in regards to apparent volume status, those in whom pre-capillary pulmonary hypertension $(\mathrm{PH})$ could be expected were referred for right heart catheterisation (RHC) with angiography to assess for chronic thromboembolic pulmonary hypertension $(\mathrm{CTEPH})$ after $\geqslant 3$ months of appropriate anticoagulation. Patients were classified as having confirmed CTEPH based on the haemodynamic definition in the 5th World Symposium on Pulmonary Hypertension [18] in the presence of perfusion defects with angiography. Patients were classified as having "suspected CTEPH" if the clinical assessment strongly suggested CTEPH but patients declined catheterisation for sensible reasons like advanced neurological disease (dementia).

\section{Statistical analysis}

Variables are expressed as mean $\pm \mathrm{SD}$ or median (interquartile range). Non-parametric testing was performed with Mann-Whitney and Kruskal-Wallis testing using SAS 9.4 (SAS Institute Inc., Cary, NC, USA). Statistical significance was defined as $\mathrm{p}<0.05$. 


\section{Results}

Of 122 patients, 107 attended follow-up appointments at our PH clinic 2-4 months after management of acute intermediate- or high-risk PE. Patient demographics and presentation are shown in tables 1 and 2. Of the 15 that were not followed up, two died before their scheduled appointment because of complications related to malignancy (not VTE or bleeding mediated), eight were never scheduled and five did not keep their appointments. For the 13 patients not seen in the clinic, electronic medical record evidence showed them to be alive and without evidence of recurrent pulmonary emboli or major bleeding. The majority of patients who were followed up were obese with an average BMI of $35.7 \mathrm{~kg} \cdot \mathrm{m}^{-2}$ (table 1); 32 patients had a $\mathrm{BMI} \geqslant 40 \mathrm{~kg} \cdot \mathrm{m}^{-2}$ (morbid obesity) and 39 patients had a BMI of $30-39 \mathrm{~kg} \cdot \mathrm{m}^{-2}$ (obese) (table 1). The most common treatment during hospitalisation was anticoagulation with heparin (either unfractionated or low-molecular weight), while $28 \%$ received advanced therapies (e.g. thrombolytics, table 2 ). At discharge, $67 \%$ of patients were prescribed a DOAC and $26 \%$ were prescribed warfarin (table 2).

\section{Recurrent events and residual perfusion defect}

Between hospital discharge and 6 months after the index event, no patients had diagnostic evidence for recurrent $\mathrm{PE}$ or deep vein thrombosis. At follow-up, 68 patients who were taking DOACs and 35 taking warfarin or low-molecular weight heparin had V/Q testing regardless of symptoms (four patients were evaluated without V/Q imaging). 50 patients (49\%) had residual unmatched perfusion defects. There was no difference between patients treated with a DOAC or with conventional anticoagulation (33 out of 68 (49\%) versus 17 out of 35 (49\%), $\mathrm{p}=0.99)$. Similarly, there was no difference in the rate of residual unmatched perfusion defects in the subset of morbidly obese patients treated with a DOAC or conventional anticoagulation $(9(47 \%)$ versus $6(50 \%), \mathrm{p}=0.99$, table 3$)$.

\section{CTEPH}

At follow-up, 59 patients (55\%) reported self-limited activity because of breathlessness. Based on symptoms and imaging concerning for CTEPH, CTEPH was diagnosed in eight out of 11 patients who underwent RHC after the requisite 3 months of anticoagulation. One patient was directly referred for CTEPH surgery after index hospitalisation without being seen in clinic, giving a total of nine patients diagnosed with CTEPH (table 3). RHC and angiography were recommended in 11 patients who declined testing because of preference or severe cognitive impairment. Including these patients who declined testing resulted in an estimated prevalence of confirmed or suspected CTEPH after intermediate- or high-risk PE of $>15 \%$ (15-20 patients) (table 3$)$.

\section{TABLE 1 Baseline demographics}

\begin{tabular}{|c|c|c|c|}
\hline & $\mathrm{BMI}<30 \mathrm{~kg} \cdot \mathrm{m}^{-2}$ & BMI $30-39 \mathrm{~kg} \cdot \mathrm{m}^{-2}$ & $\mathrm{BMI} \geqslant 40 \mathrm{~kg} \cdot \mathrm{m}^{-2}$ \\
\hline Subjects n & 36 & 39 & 32 \\
\hline Age years & 69 (28-93) & $62(29-85)$ & 50 (25-75) \\
\hline Male & $23(64)$ & $21(54)$ & $14(44)$ \\
\hline Caucasian & $28(78)$ & 32 (82) & 25 (78) \\
\hline $\mathrm{BMI} \mathrm{kg} \cdot \mathrm{m}^{-2}$ & $27(23-29)$ & $34(30-39)$ & $46(40-68)$ \\
\hline Active smoking & $3(8)$ & $5(13)$ & $4(13)$ \\
\hline HFpEF & 9 (25) & $15(38)$ & $28(88)$ \\
\hline CAD & $4(11)$ & $2(5)$ & $4(13)$ \\
\hline CKD>II & $1(3)$ & $2(5)$ & $2(6)$ \\
\hline Atrial fibrillation & $3(8)$ & $4(10)$ & $3(9)$ \\
\hline Diabetes & $6(17)$ & $10(26)$ & $9(28)$ \\
\hline Hypertension & 14 (39) & $25(64)$ & $23(72)$ \\
\hline Splenectomy & $2(6)$ & 2 (5) & $2(6)$ \\
\hline Hypothyroidism & $5(14)$ & $8(21)$ & $32(6)$ \\
\hline OSA $^{\#}$ & 7 (19) & $11(28)$ & $20(63)$ \\
\hline Provoked & 14 (39) & $11(28)$ & $9(28)$ \\
\hline Post-operative & $6(17)$ & $9(23)$ & $6(28)$ \\
\hline Active malignancy & $6(17)$ & $1(3)$ & 0 \\
\hline Prior VTE & $10(28)$ & $7(18)$ & $5(16)$ \\
\hline Prior gastric bypass surgery (Rou-En-Y) & 1 (3) & $2(5)$ & $2(6)$ \\
\hline
\end{tabular}




\section{TABLE 2 Clinical information at presentation and during hospitalisation}

\begin{tabular}{|c|c|c|c|}
\hline & $\mathrm{BMI}<30 \mathrm{~kg} \cdot \mathrm{m}^{-2}$ & BMI $30-39 \mathrm{~kg} \cdot \mathrm{m}^{-2}$ & $\mathrm{BMI} \geqslant 40 \mathrm{~kg} \cdot \mathrm{m}^{-2}$ \\
\hline Subjects $\mathbf{n}$ & 36 & 39 & 32 \\
\hline \multicolumn{4}{|l|}{ Pulmonary embolus } \\
\hline High risk & $4(11)$ & $7(18)$ & $1(3)$ \\
\hline Intermediate risk & 32 (89) & $32(82)$ & 31 (97) \\
\hline Duration of symptoms days & $3(1-15)$ & $1(1-4)$ & $3(1-7)$ \\
\hline \multicolumn{4}{|l|}{ Signs/symptoms at presentation } \\
\hline Cardiac arrest & 1 (3) & $2(5)$ & 0 \\
\hline Chest pain & $13(36)$ & $19(49)$ & 12 (38) \\
\hline Syncope & $9(25)$ & $7(18)$ & $5(16)$ \\
\hline Pre-syncope & $6(17)$ & $14(36)$ & $9(28)$ \\
\hline Dyspnoea & $29(81)$ & $36(92)$ & $29(91)$ \\
\hline Hypoxia & $20(56)$ & $29(74)$ & $18(56)$ \\
\hline Admission NT-proBNP $\mathrm{pg} \cdot \mathrm{mL}^{-1}$ & $1698(485-4497)$ & $908(473-2540)$ & $1161(224-3564)$ \\
\hline \multicolumn{4}{|l|}{ CT imaging } \\
\hline Saddle & 12 (33) & $20(51)$ & $6(28)$ \\
\hline Main & $10(28)$ & $9(23)$ & 12 (38) \\
\hline Lobar & $11(31)$ & $7(18)$ & $11(31)$ \\
\hline Right heart enlargement & 30 (83) & $31(79)$ & $23(72)$ \\
\hline \multicolumn{4}{|l|}{ Echocardiogram } \\
\hline Moderate/severe RV enlargement & $23(63)$ & $24(62)$ & $22(69)$ \\
\hline Moderate/severe RV dysfunction & $20(56)$ & $25(64)$ & $20(63)$ \\
\hline $\begin{array}{l}\text { Confirmed DVT on ultrasound } \\
\text { treatment }\end{array}$ & $20(56)$ & $22(56)$ & 19 (59) \\
\hline Anticoagulation only & $26(72)$ & $23(59)$ & $28(88)$ \\
\hline Advanced therapies $\#$ & $10(28)$ & $16(41)$ & $4(12)$ \\
\hline Hospital stay days & $5(2-8)$ & $5(3-11)$ & $4(3-7)$ \\
\hline \multicolumn{4}{|l|}{ Anticoagulation on discharge } \\
\hline DOAC & $24(67)$ & $27(69)$ & 19 (59) \\
\hline Apixaban & 14 (39) & 15 (38) & $8(25)$ \\
\hline Rivaroxaban & $10(28)$ & $12(31)$ & $11(34)$ \\
\hline Vitamin $\mathrm{K}$ antagonist & $8(22)$ & $10(26)$ & 10 (31) \\
\hline \multicolumn{4}{|c|}{$\begin{array}{l}\text { Data presented as mean (interquartile range) or } \mathrm{n}(\%) \text {, unless otherwise indicated. BMI: body mass index; } \\
\text { NT-proBNP: N-terminal pro-brain natriuretic peptide; CT: computed tomography; RV: right ventricle; DVT: } \\
\text { deep vein thrombosis; DOAC: direct oral anticoagulants. " } \text { : systemic thrombolysis, catheter-directed lysis, } \\
\text { surgical embolectomy. }\end{array}$} \\
\hline
\end{tabular}

There was no difference in the rate of confirmed CTEPH whether patients were treated with DOACs or conventional anticoagulation (4 (6\%) versus $4(11 \%), \mathrm{p}=0.45)$. There was no difference in the rate of confirmed CTEPH in morbid obesity when comparing DOACs with conventional anticoagulation (1 (5\%) versus 1 (8\%), $\mathrm{p}=0.99$, table 3$)$. Even assuming that all patients who were recommended for further testing had CTEPH, patients with morbid obesity treated with a DOAC did not have a higher rate of CTEPH than those treated with conventional anticoagulation therapy $(2(11 \%)$ versus $5(41 \%), p=0.06)$. There was no difference in the rate of CTEPH in the obese and non-obese patients based on type of anticoagulation.

\section{Right ventricular recovery}

At the time of acute presentation, the majority of patients (63\%) had moderate or severe right ventricle enlargement without differences between obese and non-obese patients (table 2). At follow-up, 106 patients had an echocardiogram: 69 treated with a DOAC (19 morbidly obese) and 37 treated with conventional warfarin or enoxaparin anticoagulation (13 morbidly obese) (table 3). In total, 97 patients had a normal or mildly enlarged right ventricle, and nine had a moderately enlarged right ventricle (table 3 ). 102 patients had normal or mildly reduced right ventricular function, and four had moderately reduced function (table 3).

There was no difference in the rate of having a normal or mildly enlarged right ventricle at follow-up when comparing DOACs to conventional therapy (63 (92\%) versus 34 (92\%), table 3). 18 (95\%) morbidly obese patients treated with a DOAC had a normal or mildly enlarged right ventricle at follow-up compared to 12 (92\%) morbidly obese patients treated with warfarin or enoxaparin (table 3). Similarly, there were no differences between the obese and non-obese groups. 


\section{TABLE 3 Clinical assessment 2-4 months after pulmonary embolus}

\begin{tabular}{|c|c|c|c|}
\hline & $\mathrm{BMI}<30 \mathrm{~kg} \cdot \mathrm{m}^{-2}$ & BMI $30-39 \mathrm{~kg} \cdot \mathrm{m}^{-2}$ & $\mathrm{BMI} \geqslant 40 \mathrm{~kg} \cdot \mathrm{m}^{-2}$ \\
\hline Subjects $\mathrm{n}$ & 36 & 39 & 32 \\
\hline Self-limiting activity & $15(42)$ & $22(56)$ & 22 (69) \\
\hline NYHA functional class & 34 & 35 & 29 \\
\hline I & $16(47)$ & $18(51)$ & $5(17)$ \\
\hline II & $16(47)$ & $15(43)$ & $19(66)$ \\
\hline III & $2(6)$ & $2(6)$ & $5(17)$ \\
\hline 6MWT m & $395(308-496)$ & $408(351-482)$ & $338(219-407)$ \\
\hline Decompensated heart failure $\#$ & $6(17)$ & $13(33)$ & $22(69)$ \\
\hline Iron deficiency ${ }^{\text {I }}$ & $7(19)$ & $10(26)$ & $14(44)$ \\
\hline New OSA diagnosis at follow-up & $3(8)$ & $12(31)$ & $6(19)$ \\
\hline Sleep study recommended but not completed & $8(22)$ & $9(23)$ & $7(22)$ \\
\hline Echocardiogram & 35 & 39 & 32 \\
\hline \multicolumn{4}{|l|}{ RV size } \\
\hline Normal & $23(66)$ & $29(74)$ & $14(44)$ \\
\hline Mild enlargement & $8(23)$ & $7(18)$ & $16(50)$ \\
\hline \multicolumn{4}{|l|}{ RV dysfunction } \\
\hline None & $24(69)$ & $26(67)$ & $23(72)$ \\
\hline Mild & $10(29)$ & $13(33)$ & $6(19)$ \\
\hline Residual unmatched perfusion defects ${ }^{+}$ & $18(50)$ & $17(44)$ & $15(47)$ \\
\hline Recurrent VTE $\S$ & $1(3)$ & 0 & 0 \\
\hline Confirmed CTEPH & $5(14)$ & $2(5)$ & $2(6)$ \\
\hline Suspected CTEPH & $2(5)$ & $4(10)$ & $5(16)$ \\
\hline Total CTEPH & $7(19)$ & $6(15)$ & $7(22)$ \\
\hline \multicolumn{4}{|c|}{$\begin{array}{l}\text { Data presented as mean (interquartile range) or } \mathrm{n}(\%) \text {, unless otherwise indicated. BMI: body mass index; } \\
\text { NYHA: New York Heart Association; 6MWT: 6-min walk test; OSA: obstructive sleep apnoea; RV: right } \\
\text { ventricle; VTE: venous thromboembolism; CTEPH: chronic thromboembolic pulmonary hypertension. } \\
\text { \#: clinical diagnosis; }{ }^{\text {n }} \text { criteria from Ferinject Assessment in Patients With Iron Deficiency and Chronic } \\
\text { Heart Failure (FAIR-HF) trial; }{ }^{+}: 100 \text { patients underwent V/Q testing (three patients in the heparin group and }\end{array}$} \\
\hline
\end{tabular}

There was no difference in the rate of recovery in right ventricular function (normal or mildly reduced at follow-up) comparing DOACs to conventional anticoagulation (68 (99\%) versus 34 (92\%)). 18 of 19 (95\%) morbidly obese patients treated with DOACs had normal or mildly impaired right ventricular function while 11 of $13(84 \%)$ treated with conventional anticoagulation had a normal or mildly impaired right ventricle $(\mathrm{p}=0.55)$.

\section{N-terminal pro-brain natriuretic peptide and 6-min walk assessment}

At follow-up, 55 patients had their levels of N-terminal pro-brain natriuretic peptide (NT-proBNP) assessed because of breathlessness or signs of heart failure: 22 morbidly obese (13 on DOAC therapy and nine on conventional therapy), 18 obese (10 on DOAC therapy and eight on conventional therapy) and 15 non-obese (10 on DOAC therapy and five on conventional therapy). Owing to staffing limitations, only 58 patients completed a 6-min walk test (6MWT) regardless of symptoms, 16 of whom were morbidly obese (nine on DOAC therapy and seven on conventional therapy).

There was no difference in NT-proBNP when comparing patients treated with DOAC therapy and patients treated with conventional therapy $\left(97 \mathrm{pg} \cdot \mathrm{mL}^{-1}\right.$ versus $\left.167 \mathrm{pg} \cdot \mathrm{mL}^{-1}, \mathrm{p}=0.13\right)$, for the entire cohort. There was no difference in NT-proBNP based on DOAC versus conventional therapy in morbid obesity (97 $\mathrm{pg} \cdot \mathrm{mL}^{-1}$ versus $183 \mathrm{pg} \cdot \mathrm{mL}^{-1}, \mathrm{p}=0.19$ ). There was no difference in $6 \mathrm{MWT}$ distance based on DOAC versus conventional therapy ( $399 \mathrm{~m}$ versus $338 \mathrm{~m}, \mathrm{p}=0.09$ ), for the entire cohort or for the three subgroups based on BMI.

\section{Bleeding}

There were two patients on non-DOAC therapy with bleeding complications that required intervention. One morbidly obese patient treated with warfarin developed haematuria in the setting of an elevated international normalised ratio and required hospitalisation. Another morbidly obese patient developed a spontaneous retroperitoneal bleed on low-molecular weight heparin that required hospitalisation. No patients on DOAC therapy were hospitalised owing to bleeding complications. One morbidly obese patient 
required a dose reduction from $20 \mathrm{mg}$ to $10 \mathrm{mg}$ of rivaroxaban because of gingival bleeding in the setting of poor dentition. The bleeding stopped and there were no further complications at this dose.

\section{Discussion}

In an observational cohort of higher-risk PE patients, DOAC therapy in morbidly obese patients was not associated with an increased risk of recurrent VTE compared to warfarin anticoagulation therapy within 6 months of management of acute PE, and these higher-risk patients had similar recovery of right ventricle function on DOAC therapy as those treated with warfarin (even among morbidly obese patients). This work is strengthened by the rigorous follow-up and imaging acquisition in almost all patients regardless of symptoms.

Fixed-dose DOAC therapies have greatly simplified management of acute PE by preventing recurrent VTE without the need for laboratory monitoring and the associated effort to make warfarin dose adjustments. For patients, the "real-world" rates of bleeding are low [19], and there is relatively little concern for drug-diet or drug-drug interactions [20]. The initial concern about using fixed-dose DOAC therapy in morbid obesity was understandable. Both unfractionated and low-molecular weight heparin are weight-based drugs, and vitamin $\mathrm{K}$ antagonist doses are typically higher in morbid obesity [8]. Theoretically, it would make sense that morbidly obese patients would require higher doses of DOAC therapy based on a fixed dose diluted in a larger volume of distribution, but limited pharmacokinetic and pharmacodynamic studies evaluating DOAC in morbid obesity suggest weight does not influence dosing [21-25]. Furthermore, there is no clear relationship between drug levels and clinical outcomes like VTE recurrence or bleeding [3-6]. No therapeutic range of Xa inhibition is established for DOAC. Given the difficulty in achieving therapeutic levels with warfarin [8], having a simplified option could decrease recurrent events.

The current consensus guidelines from ISTH [7] and the European Society of Cardiology [26] both caution against using DOAC therapy for patients with a BMI $>40 \mathrm{~kg} \cdot \mathrm{m}^{-2}$; if DOACs are used, these documents recommend measuring anti-Xa activity despite the fact that no therapeutic range has been established. The American Society of Hematology does not address morbid obesity in their 2018 VTE guidelines [27]. Papers being published today still caution against DOAC use in morbidly obese patients owing to the lack of clinical data, with calls for prospective trials to be completed before DOAC use can be recommended in this population [28-30]. However, at least one meta-analysis found no reduction in efficacy in the registration trials when looking at obese versus non-obese patients [31]. To the best of our knowledge, there are no active clinical trials evaluating DOAC therapy for VTE in morbid obesity (clinicaltrials.gov, October 2020).

The majority of patients included in the original DOAC clinical trials were low-risk VTE and not obese. However, it is important to note that neither BMI nor weight was an exclusionary criterion in the registration trials. A meta-analysis determined that $20 \%$ of participants in the registration trials were "high body weight" at randomisation (either $>100 \mathrm{~kg}$ or $>90 \mathrm{~kg}$ ) [31]. None of the registration trials reported event rates specifically in morbid obesity, but they did report no differences in recurrent events in the high body weight groups treated with DOAC versus conventional therapy [3-6].

Recurrent VTE events often occur within 3-6 months at a rate of 4\%-8\% [32, 33] and typically present in a similar manner as the index event [34,35]. With obesity being a risk factor for initial [11-13] and recurrent [14] VTE, if effective anticoagulation was not provided, the observed VTE recurrence rate would likely be much higher than the reported baseline of $\sim 4 \%-8 \%$. We did not observe an elevated recurrence rate in our cohort. There is evolving retrospective data on the efficacy of DOAC therapy in morbid obesity. KUSHNir et al. [36] used single-centre chart review and determined a 2\% risk for recurrent VTE in 366 morbidly obese $\left(\mathrm{BMI}>40 \mathrm{~kg} \cdot \mathrm{m}^{-2}\right)$ patients with any DOAC-treated VTE event. Using two US claims databases, Spyropoulos et al. [37] found a similar rate of risk of recurrent thrombotic events in morbid obesity. Although both studies relied on coding, their findings are real-world evidence that DOACs are effective in morbid obesity. We do not know if some of their recurrent VTE could have been unrecognised CTEPH or chronic clot.

We complement these larger studies with rigorous clinical follow-up and detailed chart review including echocardiogram, V/Q scan and RHC. We did not observe any recurrent PE within the first year in any patient, regardless of weight group or type of anticoagulation. We were able to differentiate CTEPH from recurrent PE. Furthermore, we did not observe any difference in the resolution of thrombotic disease on perfusion lung scanning, and DOAC-treated patients were just as likely to achieve right ventricle recovery (an indirect measure that the pulmonary circulation is no longer obstructed) after higher-risk PE. Our numbers are small, but DOACs did not appear to leave patients at higher risk for CTEPH. None of the registration clinical trials reported rates of CTEPH development, and given the large numbers of patients 
involved, CTEPH would be expected in some patients. Our data strengthen a growing body of literature supporting the clinical efficacy of DOAC therapy in morbid obesity because none of the previously reported studies detailed follow-up data on imaging and physiological recovery.

There are limitations to our study. We have data on a small number of morbidly obese patients on DOAC therapy that took 2 years to collect. However, given that this is a high-risk group, DOAC failure with recurrent events should have been observed. Our data are observational and anticoagulation was chosen based on the preference of the discharging attending physician and patient. Peak and trough drug concentrations were not measured, and we have no measurements of anti-Xa levels. We only included patients who had an intermediate- or high-risk PE. We did not include atrial fibrillation in our analysis and therefore our results may not be applicable to patients with $\mathrm{BMI}>40 \mathrm{~kg} \cdot \mathrm{m}^{-2}$ and atrial fibrillation.

In conclusion, we found that DOAC therapy does not put patients with morbid obesity at higher risk for recurrent VTE after intermediate- or high-risk PE compared to warfarin anticoagulation; we observed similar outcomes in obese and non-obese patients. Perfusion lung scanning did not suggest a difference in the rate of thrombus resolution, and echocardiography suggested similar rates of right ventricular recovery regardless of anticoagulation choice. In patients with $\mathrm{PE}$, we believe that the available evidence makes DOAC therapy a reasonable option even in morbid obesity; we propose prospective clinical trials to address this directly.

Author contributions: D.J. Lachant, C. Bach, A. Fe, R.J. White and N.A. Lachant all contributed to the study design, analysis of the results and writing the manuscript, and approved the manuscript.

Conflict of interest: None declared.

\section{References}

1 Aryal MR, Gosain R, Donato A, et al. Systematic review and meta-analysis of the efficacy and safety of apixaban compared to rivaroxaban in acute VTE in the real world. Blood Adv 2019; 3: 2381-2387.

2 Kearon C, Akl EA, Ornelas J, et al. Antithrombotic therapy for VTE disease: CHEST guideline and expert panel report. Chest 2016; 149: 315-352.

3 Schulman S, Kearon C, Kakkar AK, et al. Dabigatran versus warfarin in the treatment of acute venous thromboembolism. N Engl J Med 2009; 361: 2342-2352.

4 EINSTEIN-PE Investigators, Büller HR, Prins $\mathrm{H}$, et al. Oral rivaroxaban for the treatment of symptomatic pulmonary embolism. N Engl J Med 2012; 366: 1287-1297.

5 Agnelli G, Buller HR, Cohen A, et al. Oral apixaban for the treatment of acute venous thromboembolism. $N$ Engl J Med 2013; 369: 799-808.

6 Hokusai-VTE Investigators, Büller HR, Décousus $\mathrm{H}$, et al. Edoxaban versus warfarin for the treatment of symptomatic venous thromboembolism. N Engl J Med 2013; 369: 1406-1415.

7 Martin K, Beyer-Westendorf J, Davidson BL, et al. Use of the direct oral anticoagulants in obese patients: guidance from the SSC of the ISTH. J Thromb Haemost 2016; 14: 1308-1313.

8 Wallace JL, Reaves $\mathrm{AB}$, Tolley EA, et al. Comparison of initial warfarin response in obese patients versus non-obese patients. J Thromb Thrombolysis 2013; 36: 96-101.

9 Hales CM, Carroll MD, Fryar CD, et al. Prevalence of obesity among adults and youth: United States, 2015-2016. NCHS Data Brief 2017; 288: 1-8.

10 Sturm R, Hattori A. Morbid obesity rates continue to rise rapidly in the United States. Int J Obes (Lond) 2013; 37: 889-891.

11 Ageno W, Becattini C, Brighton $\mathrm{T}$, et al. Cardiovascular risk factors and venous thromboembolism: a meta-analysis. Circulation 2008; 117: 93-102.

12 Borch KH, Braekkan SK, Mathiesen EB, et al. Abdominal obesity is essential for the risk of venous thromboembolism in the metabolic syndrome: the Tromso study. J Thromb Haemost 2009; 7: 739-745.

13 Stein PD, Beemath A, Olson RE. Obesity as a risk factor in venous thromboembolism. Am J Med 2005; 118 978-980.

14 Stewart LK, Kline JA. Metabolic syndrome increases risk of venous thromboembolism recurrence after acute deep vein thrombosis. Blood Adv 2020; 4: 127-135.

15 Hossain MA, Amin A, Paul A, et al. Recognizing obesity in adult hospitalized patients: a retrospective cohort study assessing rates of documentation and prevalence of obesity. J Clin Med 2018; 7: 203.

16 Konstantinides SV, Barco S, Lankeit M, et al. Management of pulmonary embolism: an update. J Am Coll Cardiol 2016; 67: 976-990

17 Lachant D, Bach C, Wilson B, et al. Clinical and imaging outcomes after intermediate- or high-risk pulmonary embolus. Pulm Circ 2020; 10: 2045894020952019.

18 Kim NH, Delcroix M, Jenkins DP, et al. Chronic thromboembolic pulmonary hypertension. J Am Coll Cardiol 2013; 62: Suppl. 25, D92-D99.

19 Jun M, Lix LM, Durand M, et al. Comparative safety of direct oral anticoagulants and warfarin in venous thromboembolism: multicentre, population based, observational study. BMJ 2017; 359: j4323.

20 Coulis AA, Mackey WC. A review of the efficacy and safety profiles of the novel oral anticoagulants in the treatment and prevention of venous thromboembolism. Clin Ther 2018; 40: 2140-2167.

21 Kubitza D, Becka M, Zuehlsdorf $\mathrm{M}$, et al. Body weight has limited influence on the safety, tolerability, pharmacokinetics, or pharmacodynamics of rivaroxaban (BAY 59-7939) in healthy subjects. J Clin Pharmacol 2007; 47: 218-226. 
22 Upreti VV, Wang J, Barrett YC, et al. Effect of extremes of body weight on the pharmacokinetics, pharmacodynamics, safety and tolerability of apixaban in healthy subjects. Br J Clin Pharmacol 2013; 76: 908-916.

23 Arachchillage D, Reynolds R, Devey T, et al. Effect of extremes of body weight on drug level in patient treated with standard dose of rivaroxaban for venous thromboembolism; real life experience. Thromb Res 2016; 147: $32-35$.

24 Fietz C, Michels G, Muller C, et al. Monitoring of apixaban in a super obese patient. Am J Med 2019; 132: e15-e16.

25 Piran S, Traquair H, Chan N, et al. Peak plasma concentration of direct oral anticoagulants in obese patients weighing over 120 kilograms: a retrospective study. Res Pract Thromb Haemost 2018; 2: 684-688.

26 Rocca B, Fox KAA, Ajjan RA, et al. Antithrombotic therapy and body mass: an expert position paper of the ESC Working Group on Thrombosis. Eur Heart J 2018; 39: 1672-1686f.

27 Witt DM, Nieuwlaat R, Clark NP, et al. American Society of Hematology 2018 guidelines for management of venous thromboembolism: optimal management of anticoagulation therapy. Blood Adv 2018; 2: 3257-3291.

28 Salazar Adum JP, Golemi I, Paz LH, et al. Venous thromboembolism controversies. Dis Mon 2018; 64: 408-444.

29 Moll S, Crona DJ, Martin K. Direct oral anticoagulants in extremely obese patients: OK to use? Res Pract Thromb Haemost 2019; 3: 152-155.

30 Wang TF, Carrier M. How I treat obese patients with oral anticoagulants. Blood 2020; 135: 904-911.

31 Di Minno MN, Lupoli R, Di Minno A, et al. Effect of body weight on efficacy and safety of direct oral anticoagulants in the treatment of patients with acute venous thromboembolism: a meta-analysis of randomized controlled trials. Ann Med 2015; 47: 61-68.

32 Heit JA, Lahr BD, Petterson TM, et al. Heparin and warfarin anticoagulation intensity as predictors of recurrence after deep vein thrombosis or pulmonary embolism: a population-based cohort study. Blood 2011; 118 4992-4999.

33 Bott-Kitslaar DM, McBane RD, Casanegra AI, et al. Apixaban and rivaroxaban in patients with acute venous thromboembolism. Mayo Clin Proc 2019; 94: 1242-1252.

34 Eichinger S, Weltermann A, Minar E, et al. Symptomatic pulmonary embolism and the risk of recurrent venous thromboembolism. Arch Intern Med 2004; 164: 92-96.

35 Murin S, Romano PS, White RH. Comparison of outcomes after hospitalization for deep venous thrombosis or pulmonary embolism. Thromb Haemost 2002; 88: 407-414.

36 Kushnir M, Choi Y, Eisenberg R, et al. Efficacy and safety of direct oral factor Xa inhibitors compared with warfarin in patients with morbid obesity: a single-centre, retrospective analysis of chart data. Lancet Haematol 2019; 6: e359-e365.

37 Spyropoulos AC, Ashton V, Chen Y-W, et al. Rivaroxaban versus warfarin treatment among morbidly obese patients with venous thromboembolism: comparative effectiveness, safety, and costs. Thromb Res 2019; 182: $159-166$. 